\title{
Article \\ Mechanistic Insights into Hydrodeoxygenation of Acetone over Mo/HZSM-5 Bifunctional Catalyst for the Production of Hydrocarbons
}

\author{
Kai Miao, Tan Li, Jing Su, Cong Wang and Kaige Wang * \\ State Key Laboratory of Clean Energy Utilization, Zhejiang University, Hangzhou 310027, China;

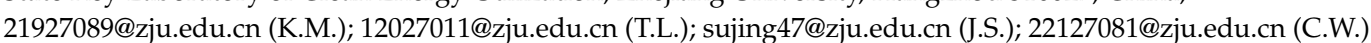 \\ * Correspondence: kaigewang@zju.edu.cn
}

Citation: Miao, K.; Li, T.; Su, J.; Wang, C.; Wang, K. Mechanistic Insights into Hydrodeoxygenation of Acetone over Mo/HZSM-5 Bifunctional

Catalyst for the Production of

Hydrocarbons. Energies 2022, 15, 53.

https://doi.org/10.3390/en15010053

Academic Editors: Abel Rouboa and Eliseu Monteiro

Received: 7 December 2021

Accepted: 20 December 2021

Published: 22 December 2021

Publisher's Note: MDPI stays neutral with regard to jurisdictional claims in published maps and institutional affiliations.

Copyright: (C) 2021 by the authors. Licensee MDPI, Basel, Switzerland. This article is an open access article distributed under the terms and conditions of the Creative Commons Attribution (CC BY) license (https:// creativecommons.org/licenses/by/ $4.0 /)$

\begin{abstract}
Catalytic hydropyrolysis via the introduction of external hydrogen into catalytic pyrolysis process using hydrodeoxygenation catalysts is one of the major approaches of bio-oil upgrading. In this study, hydrodeoxygenation of acetone over Mo/HZSM-5 and HZSM-5 were investigated with focus on the influence of hydrogen pressure and catalyst deactivation. It is found that doped $\mathrm{MoO}_{3}$ could prolong the catalyst activity due to the suppression of coke formation. The influence of hydrogen pressure on catalytic HDO of acetone was further studied. Hydrogen pressure of 30 bar effectively prolonged catalyst activity while decreased the coke deposition over catalyst. The coke formation over the HZSM- 5 and Mo/HZSM- 5 under 30 bar hydrogen pressure decreased $66 \%$ and $83 \%$, respectively, compared to that under atmospheric hydrogen pressure. Compared to the test with the HZSM-5, 35\% higher yield of aliphatics and 60\% lower coke were obtained from the Mo/HZSM-5 under 30 bar hydrogen pressure. Characterization of the spent Mo/HZSM- 5 catalyst revealed the deactivation was mainly due to the carbon deposition blocking the micropores and Bronsted acid sites. Mo/HZSM-5 was proved to be potentially enhanced production of hydrocarbons.
\end{abstract}

Keywords: hydrodeoxygenation; biomass; hydropyrolysis; $\mathrm{MoO}_{3}$; bifunctional catalysts

\section{Introduction}

Lignocellulosic biomass, as a potentially $\mathrm{CO}_{2}$ neutral energy source, has gained widespread attention [1]. Fast pyrolysis is considered to be one of the most effective biomass conversion technologies [2]. However, the bio-oil, produced from biomass fast pyrolysis, has a number of undesirable properties such as low stability, low heating value and high acidity [3,4]. These disadvantages are mainly caused by the high oxygen content of biomass, which hinders the crude bio-oil from integrating with the downstream upgrading process [5]. Catalytic pyrolysis using some deoxygenated catalysts such as zeolites is an attractive approach to remove excessive amount of oxygen [6-8]. Catalytic pyrolysis involves the cleavage of $\mathrm{C}-\mathrm{C}$ bonds related to dehydration, decarboxylation, and decarbonylation $[9,10]$. Deoxygenation is normally occurred by the formation of $\mathrm{CO}$ and $\mathrm{CO}_{2}$, which results to the carbon lose during the catalytic pyrolysis process. A significant amount of coke formation has also been reported due to the hydrogen deficient nature (low $\mathrm{H} / \mathrm{C}_{\text {eff }}$ ratio) of biomass feedstock compared to the petroleum crude $[11,12]$.

Another major upgrading approach is catalytic hydropyrolysis (CHP) via introducing external hydrogen into catalytic pyrolysis process using hydrodeoxygenation catalysts [5]. CHP was reported to increase the yield of hydrocarbons and decrease the yield of coke [13-15]. The Gas Technology Institute (GTI) developed a process named Integrated Hydropyrolysis and Hydroconversion $\left(\mathrm{IH}^{2}\right)$, which could produce gasoline and diesel range hydrocarbons directly from biomass $[16,17]$. This process includes a catalytic fast pyrolysis stage and an online upgrading stage. The catalytic fast pyrolysis was conducted in a fluid bed reactor, the pyrolysis temperatures are $335-470{ }^{\circ} \mathrm{C}$ and the hydrogen pressure is $20-25$ bar. The online upgrading stage is conducted in a fix bed reactor and the catalytic 
temperature is $345-400^{\circ} \mathrm{C}$. Liquid yield produced from this process is normally in the range of 26 to $30 \mathrm{wt} \%$ and the oxygen contents are typically lower than $0.5 \mathrm{wt} \%$, depending on the types of feedstock. Transition metal oxides based catalysts were widely applied in previous biomass hydropyrolysis studies $[18,19] . \mathrm{MoO}_{3}$ was first reported to effectively hydrodeoxygenate oxygenated compounds at atmospheric hydrogen by Román-Leshkov's group [20]. They tested several model compounds of bio-oil (e.g., acetone, anisole and 2-methylfuran) and found $\mathrm{MoO}_{3}$ had a high deoxygenating activity, especially direct hydrodeoxygenation. The mechanism of hydrodeoxygenation was reported to follow a reverse Mars-van Krevelen mechanism. In this mechanism, O-vacancy is created by reduction with hydrogen and then promotes the adsorption of oxygenates at the vacancy. Shanks et al. studied the $\mathrm{HDO}$ performance of $\mathrm{MoO}_{3}$ over cellulose pyrolysis model compounds under atmosphere pressure [21]. They reported that the deoxygenation reactivity of oxygen-containing functional groups for $\mathrm{MoO}_{3}$ followed the order: $\mathrm{C}-\mathrm{OH}>\mathrm{C}=\mathrm{O}>\mathrm{C}-\mathrm{OC}$. They supposed that ketones and alcohols tend to be directly hydrodeoxygenated and form alkenes. The alkenes may be further hydrogenated and converted to alkanes. Yuriy et al. further studied the $\mathrm{MoO}_{3}$ based heterogeneous catalysts and found $\mathrm{TiO}_{2}$ and $\mathrm{ZrO}_{2}$ could stabilize the active $\mathrm{MoO}_{3}$ species [22]. 1 to $36 \mathrm{wt} \% \mathrm{MoO}_{3}$ supported $\mathrm{ZrO}_{2}$ were also applied into the HDO process and the influence of supporting amount of heterogeneous catalysts over HDO was investigated [23]. They found that $15 \mathrm{wt} \% \mathrm{MoO}_{3}$ supported $\mathrm{ZrO}_{2}$ performed the highest catalytic activity. When the loading amount of $\mathrm{MoO}_{3}$ increased to $25 \mathrm{wt} \%$ and $36 \mathrm{wt} \%$, the crystallites of $\mathrm{MoO}_{3}$ were formed and no significant enhancement of the HDO reactivity was observed. Some researchers also investigated the metal supported zeolites bifunctional catalysts over biomass catalytic hydropyrolysis, which have both effective hydrodeoxygenation and shape selectivity properties. Yuan et al. studied the pyrolysis of different types of lignin using Mo and Ni modified ZSM-5 under both helium and hydrogen atmosphere [24]. They found that 2 wt \% Mo/ZSM-5 could remarkably increase the yield of aromatics and reduce the coke under hydrogen atmosphere, but may slightly decrease the total hydrocarbon yields. Jensen et al. evaluated a series of metal-modified ZSM-5 under hydrogen atmosphere [19]. In generally, most of the metal modified ZSM-5 enhanced the formation of hydrocarbons and decreased the coke. Rather higher deoxygenation activity was observed over Ni, Mo and Pt. They also suggested $\mathrm{MoO}_{3}$ modified ZSM- 5 should be further investigated at larger scale under hydrogen atmosphere. Sushil et al. tested four metal-modified ZSM-5 (Ni, Mo, Pt and Co) under 100-300 psi hydrogen atmosphere [25]. They found the higher hydrogen pressure have no effect on the formation of aromatics over HZSM-5. However, with the increase of hydrogen pressure, the yield of aromatics over Mo modified HZSM-5 increased. A lot of types of metal supported zeolite have been tested and proved to be able to decrease the coke formation of zeolite and promote the catalytic process. However, few studies focus on how the doped metal of bifunctional catalysts promote the hydropyrolysis process and decrease the coke formation of zeolite.

In this article, we tested HDO of biomass hydropyrolysis vapors over HZSM-5 and Mo/HZSM-5 in a fixed bed reactor. Ketone is reported to be one of the major products from non-catalytic hydropyrolysis of cellulose and biomass [26,27]. Thus, acetone was selected as a model compound of biomass hydropyrolysis vapor in this study. We also hypothesis that hydrogen pressure could promote the HDO activity over Mo/HZSM-5. HDO under three hydrogen pressure levels (10, 20 and 30 bar) were tested and the hydrodeoxygenation performance of Mo/HZSM- 5 was evaluated. The purpose of this article is to figure out the role of dispersed $\mathrm{MoO}_{3}$ in the hydrodeoxygenation process over Mo/HZSM-5 and understand how the Mo/HZSM-5 enhances the formation of desirable hydrocarbons as well as suppresses the coke deposition.

\section{Experiment Methods}

\subsection{Materials}

The acetone as feedstock was purchased from Sinopharm Chemical Reagent Co., Ltd., (Beijing, China). Zeolite ZSM-5 with a silica-to-alumina molar ratio of 25 was purchased 
from Nankai University Catalyst Co., Ltd., (Tianjin, China). The raw ZSM-5 was calcined at $550{ }^{\circ} \mathrm{C}$ for $3 \mathrm{~h}$ to form HZSM-5. Ammonium molybdate tetrahydrate $\left(\left(\mathrm{NH}_{4}\right)_{6} \mathrm{Mo}_{7} \mathrm{O}_{24} \cdot \mathrm{H}_{2} \mathrm{O}\right)$ was purchased from Aladdin (Shanghai, China). The incipient-wetness impregnation method was used for the preparation of the $5 \mathrm{wt} \% \mathrm{MoO}_{3}$ catalyst supported over HZSM-5. After impregnation, the sample was dried at $80{ }^{\circ} \mathrm{C}$ for $12 \mathrm{~h}$, then calcined at $550{ }^{\circ} \mathrm{C}$ for $5 \mathrm{~h}$ ( $5^{\circ} \mathrm{C} \mathrm{min}^{-1}$ heating rate). The catalyst particles with the size of $40-60$ mesh were used in the following experiments.

\subsection{Experiment}

The HDO reaction was conducted in a high-pressure vapor-phase fixed bed reactor system (YZ $\mu$ PBR from Yan Zheng Instrument, Shanghai, China). The scheme of the reactor system was showed in Figure 1. The reactor is a stainless steel tube of 0.5 inch OD (wall thickness $0.049 \mathrm{inch}$ ). The reactor system equipped with online product analysis, which is a bypass to the GC gas inlet controlled by two needle valves. The product vapor enters the GC inlet through a six-way injection valve and a $1 \mathrm{~mL}$ quantitative loop. The detailed description of the GC system was in the supplementary document. In a typical test, $6 \mathrm{~mL}$ $(3 \pm 0.05 \mathrm{~g})$ of catalysts supported by quartz wool was loaded in the middle of the reactor tube. Before the HDO reaction, the catalysts were pre-reduced at $400^{\circ} \mathrm{C}$ for $2 \mathrm{~h}\left(5^{\circ} \mathrm{C} \mathrm{min}-1\right.$ heating rate). The flow rate of carrier gas hydrogen was set as $180 \mathrm{~mL} \mathrm{~min}^{-1}$. The flow rate of internal standard gas argon was set as $20 \mathrm{~mL} \mathrm{~min}^{-1}$. For each run, $0.05 \mathrm{~mL} \mathrm{~min}^{-1}$ of acetone were introduced into the reactor via a syringe pump and vaporized in the preheating area. A K-type thermocouple inserted into the catalysis bed to measure the temperature, which was maintain at $400{ }^{\circ} \mathrm{C}$. The space-time $(\mathrm{W} / \mathrm{F})$ of 0.073 , expressed in $\mathrm{g}_{\text {cat }}\left(\mathrm{mmol}_{\text {feed }} \mathrm{h}^{-1}\right)^{-1}$, is defined as the ratio between the mass of the catalyst and the molar feed rate of the reactants. Each experiment was conducted for $12 \mathrm{~h}$ and sampled by GC for every one hour. The qualitative analysis of liquid products was conducted by an off-line GCMS (Agilent 7890 and MS 5977B with DB-1701 column). Quantitative analysis of products was performed by the online analysis gas chromatography (GC) with external standard method. The detailed calibration data can be found in the Table S1 in the Supplementary Materials. The coke of catalysts was analyzed by elemental analyzer. The conversion and carbon yield of products were calculated by the equations below:

$$
\text { Conversion }(\mathrm{C} \%)=\frac{\text { The mole of carbon in acetone consumed }}{\text { The mole of carbon in acetone feedstock }} \times 100 \%
$$

$$
\text { Carbon yield of product }(\mathrm{C} \%)=\frac{\text { The mole of carbon in product }}{\text { The total mole of carbon in acetone feedstock }} \times 100 \%
$$

\subsection{Catalyst Characterization}

The morphology of catalysts was examined using a $120 \mathrm{kv}$ TEM and STEM-EDS (HT7700). The surface area and porosity of the fresh and spent catalysts were measured by $\mathrm{N}_{2}$ physisorption isotherm on a Micromeritics ASAP2020 instrument. Before the measurement, the sample was vacuum degassed overnight at $350{ }^{\circ} \mathrm{C}$. Brunel-Emmett-Teller (BET) method is used for the calculation of the specific surface area. The BJH pore size distribution is used for the calculation of total pore volume and the t-plot method is used to calculate the pore volume of micropores. The acid sites of catalysts were measured by the $\mathrm{NH}_{3}-\mathrm{TPD}$ with a Micromeritics Autochem II 2920 Chemisorption analyzer. Before the measurement, the pre-reduced samples were heated to $200{ }^{\circ} \mathrm{C}$ in He with a heating rate of $20{ }^{\circ} \mathrm{C} \mathrm{min}$ mi $^{-1}$ and kept for $1 \mathrm{~h}$ to remove moisture. Then the sample was cooled down to $50{ }^{\circ} \mathrm{C}$ and flowed by $10 \mathrm{vol} \% \mathrm{NH}_{3} / \mathrm{He}$ of $20 \mathrm{~mL} \mathrm{~min}^{-1}$ for $30 \mathrm{~min}$ to absorb the $\mathrm{NH}_{3}$. After the absorption of $\mathrm{NH}_{3}$, the samples were purged by He with a flow of $20 \mathrm{~mL} \mathrm{~min}^{-1}$, then were heated to $500{ }^{\circ} \mathrm{C}$ with a heating rate of $10^{\circ} \mathrm{C} \mathrm{min}^{-1}$. A thermal conductivity detector (TCD) was used for the recording of the desorbed $\mathrm{NH}_{3}$. 


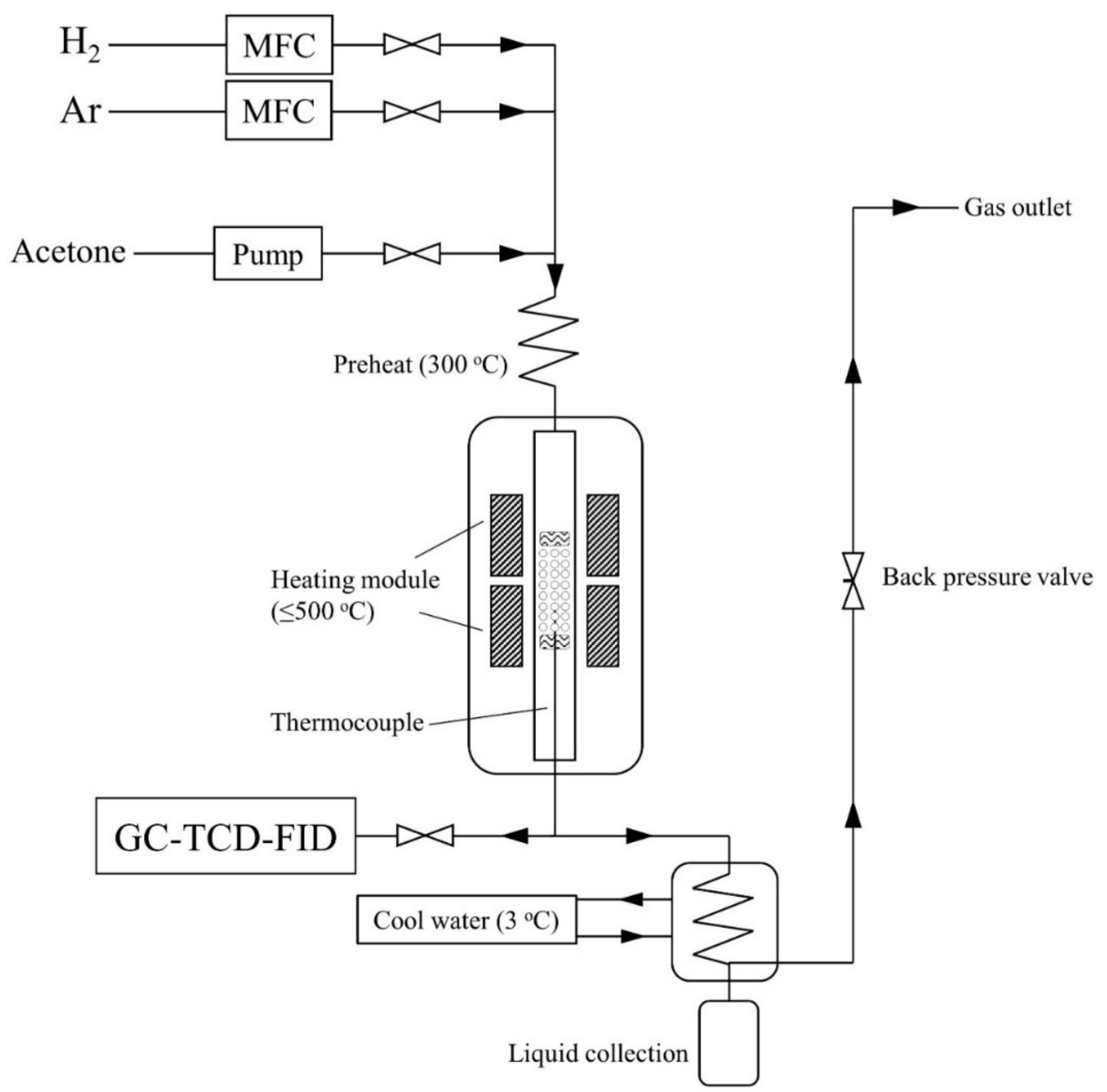

Figure 1. The diagram of fix bed reactor system.

\section{Results and Discussion}

\subsection{Catalyst Characterization}

Table 1 provides a summary of the textural properties and acidity of the catalysts. It can be seen from Table 1 that doped $\mathrm{MoO}_{3}$ decreased the surface area and pore volume of catalysts. The surface areas of $\mathrm{MoO}_{3}$ doped HZSM- 5 decreased to $367 \mathrm{~m}^{2} / \mathrm{g}$ from $397 \mathrm{~m}^{2} / \mathrm{g}$ for HZSM-5. Additionally, the total pore volume of HZSM-5 was $0.206 \mathrm{~m}^{3} / \mathrm{g}$ and that of Mo-doped HZSM- 5 was $0.188 \mathrm{~m}^{3} / \mathrm{g}$. It is noticed that both the volume of micropores and mesopores decreased by $0.009 \mathrm{~m}^{3} / \mathrm{g}$ for the doped $\mathrm{MoO}_{3}$. This trend may result from the blockage of micropores and mesopores by the doped metal oxide particles $[24,28]$.

Table 1. Summary of texture properties and acidity of fresh catalysts.

\begin{tabular}{ccc}
\hline Catalyst & HZSM-5 & $\mathbf{5 \%}$ Mo \\
\hline BET surface area $\left(\mathrm{m}^{2} / \mathrm{g}\right)$ & 397 & 367 \\
$\mathrm{a} \mathrm{V}_{\text {micro }}\left(\mathrm{m}^{3} / \mathrm{g}\right)$ & 0.122 & 0.113 \\
$\mathrm{~b} \mathrm{~V}_{\text {meso }}\left(\mathrm{m}^{3} / \mathrm{g}\right)$ & 0.084 & 0.075 \\
${ }^{\mathrm{c}} \mathrm{V}_{\text {total }}\left(\mathrm{m}^{3} / \mathrm{g}\right)$ & 0.206 & 0.188 \\
Lewis acid & & \\
Density $(\mathrm{mmol} / \mathrm{g})$ & 1.158 & 1.223 \\
Peak position $\left({ }^{\circ} \mathrm{C}\right)$ & 137.4 & 141.9 \\
Bronsted acid & & \\
Density $(\mathrm{mmol} / \mathrm{g})$ & 0.406 & 0.497 \\
Peak position $\left({ }^{\circ} \mathrm{C}\right)$ & 445.8 & 418.3 \\
\hline
\end{tabular}

a Calculated by the $t$-polt method. ${ }^{\mathrm{b}}$ Calculated by subtracting $\mathrm{V}_{\text {micro }}$ from $\mathrm{V}_{\text {total }} \cdot{ }^{\mathrm{c}}$ Calculated by the BJH method. 
From the results of $\mathrm{NH}_{3}-\mathrm{TPD}$, it is assumed that the ammonia desorbed from the low temperature can be associated with Lewis acid sites and desorbed from high desorption temperature can be associated with Bronsted acid sites [29,30]. HZSM-5 has $1.158 \mathrm{mmol} / \mathrm{g}$ of Lewis acid density and $0.406 \mathrm{mmol} / \mathrm{g}$ of Bronsted acid density. As can be seen from the Table 1, ion-exchanged with metal strongly influenced the acid site of catalysts. In the case of $\mathrm{MoO}_{3}$ doped HZSM-5, $1.223 \mathrm{mmol} / \mathrm{g}$ of Lewis acid density was observed, which is higher than that for HZSM-5. Higher Bronsted acid density was also observed from Mo/HZSM-5 (0.497 mmol/g). $\mathrm{MoO}_{3}$ also decreased the desorption peak temperature of Bronsted acid from 445.8 to $418.3^{\circ} \mathrm{C}$, which indicated the strength of Bronsted acid was decreased. This may contribute to the decreased of coke [9]. It is reported that the metal oxide particles would cover acid sites of zeolite and form new acid sites [23]. The change of acid density by doped metal oxide corresponds to the acid of metal oxide.

The results of TEM and STEM-EDS were shown in Figure 2. It can be noticed from the TEM image of HZSM-5 (Figure 2a) that the surface of HZSM-5 was rather smooth. From the TEM image of Mo/HZSM-5 (Figure 2b), we can find small protrusion on the surface of catalysts, which indicates the doped $\mathrm{MoO}_{3}$. The results of STEM-EDS of Mo/HZSM-5 (Figure 2c) showed that the Mo element (red) evenly distributed on the catalyst, which indicates the well dispersed $\mathrm{MoO}_{3}$.

(a)

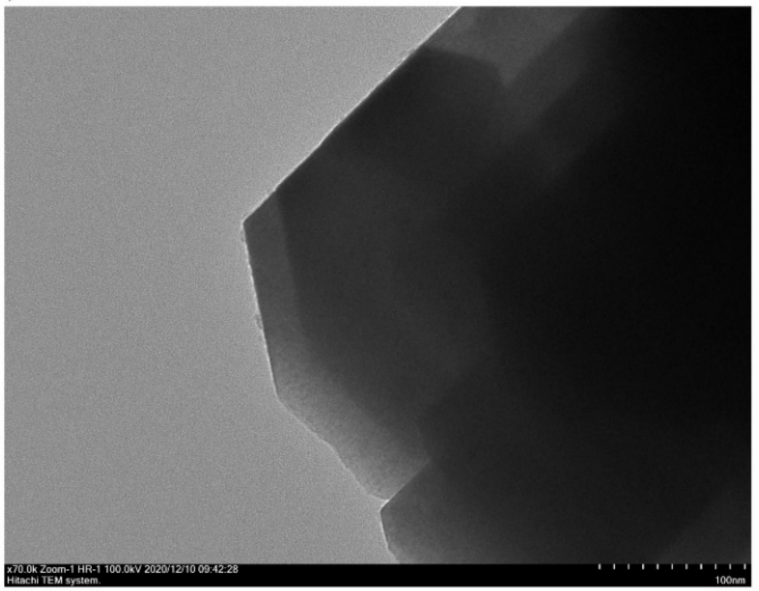

(c)

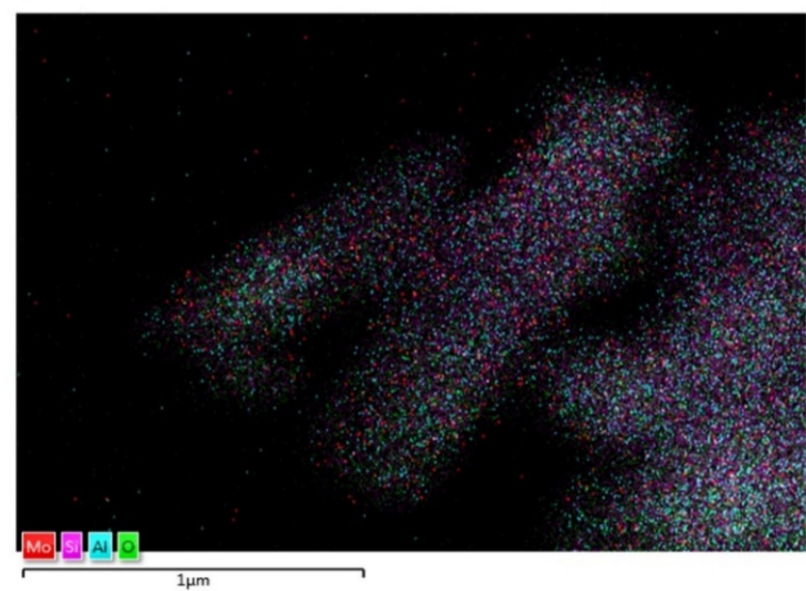

(b)
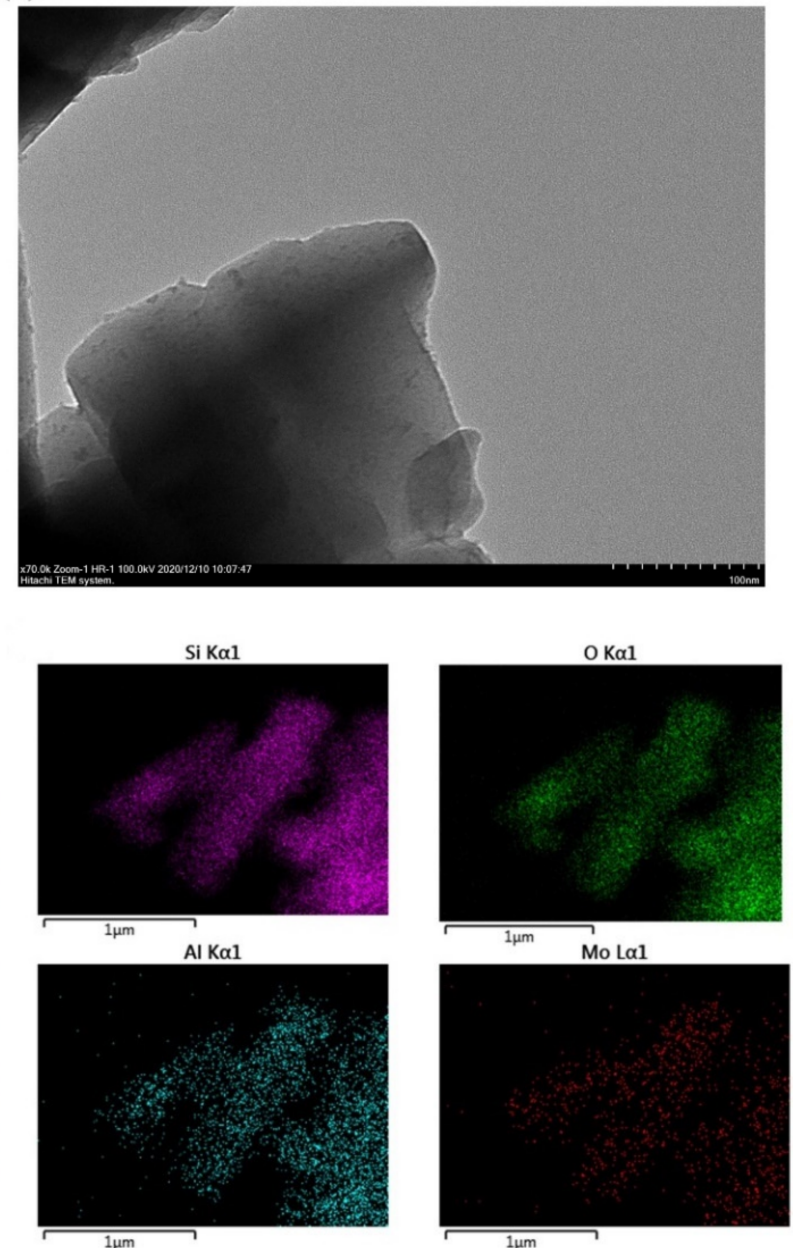

Figure 2. The results of TEM and STEM-EDS for HZSM-5 and Mo/HZSM-5. (a) TEM of HZSM-5, (b) TEM of Mo/HZSM-5, (c) STEM-EDS of Mo/HZSM-5. 


\subsection{Hydrodeoxygenation of Acetone}

\subsubsection{Atmospheric Hydrogen Pressure}

The HDO of acetone over the parent HZSM- 5 and Mo/HZSM- 5 at atmospheric hydrogen was conducted to understand how the doped metal promotes the catalytic process. The products were classified into four major groups, including alkanes (methane, ethane, propane, and butane), alkenes (ethylene, propene, butene, and hexene), BTX (benzene, toluene, and xylene), and $\mathrm{C} 9+$ (the aromatics which their carbon numbers were higher than 9, mainly alkylbenzene, alkenylbenzene and naphthalenes). Figure $3 a, b$ showed the changing trend of conversion rate and major product groups at atmospheric hydrogen pressure with the increase of TOS (time on stream). It can be noticed that the conversion rate of both catalysts was consistent at about $99.0 \%$ in the first $8 \mathrm{~h}$ of the tests, indicating a stable status and a high activity of both catalysts. When TOS increased over $9 \mathrm{~h}$, the conversion rate of both catalysts began to drop down. However, the two catalysts exhibited quite different deactivation tendency. For the HZSM-5, the conversion rate sharply decreased from $98.6 \%$ to $22.8 \%$ from $9 \mathrm{~h}$ to $12 \mathrm{~h}$. It is supposed that HZSM-5 zeolite went through a dramatical deactivation after a period of catalytic process. The major reason for the deactivation of HZSM- 5 was reported to be the coke formation and deposited on the active sites of the catalyst [31]. For the HDO test with Mo/HZSM-5, the conversion rate only decreased to $71.4 \%$ with TOS increased to $12 \mathrm{~h}$, which indicates that the Mo/ZSM5 catalyst decelerate the deactivation. The saturation tendency caused by the doped Mo could hinder the polymerization to form coke and increase the alkanes [21].

The yield of alkanes over HZSM- 5 decreased sharply from $27.9 \%$ to $4.4 \%$ in the first $9 \mathrm{~h}$ of experiment. No alkanes were detected from 9 to $12 \mathrm{~h}$ of the HDO test. In contrast, the yield of alkenes increased from $9.1 \%$ to $20.2 \%$ in the first $9 \mathrm{~h}$. However, it dropped down to $0.4 \%$ at the last three hours due to the deactivation of the HZSM-5 catalysts. The similar trend was also observed from the Mo/HZSM-5. The yield of alkanes decreased monotonically from $31.4 \%$ for TOS of $1 \mathrm{~h}$ to $0.2 \%$ toward the end of the test. In the first $8 \mathrm{~h}$ of experiments, the yield of alkenes increased from $10.3 \%$ to $30.0 \%$ with the increase of TOS, corresponding to the reduction of alkanes. Mo/HZSM- 5 obtained a higher yield of alkanes and alkenes than HZSM- 5 for all the time. The enhancement of aliphatics may be attributed to the high $\mathrm{HDO}$ activity of $\mathrm{MoO}_{3}$, which directly hydrodeoxygenated the acetone to form aliphatics. Mo/HZSM-5 not only converted more alkanes and alkenes than HZSM-5 during the whole experiment, but also kept a relatively higher catalytic activity than HZSM-5 especially at the last four hours of experiments. It can be noticed at the last four hours, test with Mo/HZSM-5 still produced a significant number of alkenes (about $25.0 \%$ from 9 to $11 \mathrm{~h}$ and $11.4 \%$ at $12 \mathrm{~h}$ ). This also indicates that doped $\mathrm{MoO}_{3}$ retarded the deactivation of catalysts and suppressed the coke formation. Figure $3 c$ exhibited the detailed product distribution of aliphatics (alkanes and alkenes) under atmospheric pressure. From Figure 3c, we can find at the beginning, the major products were $\mathrm{C} 3$ and $\mathrm{C} 4$ aliphatics, and the yield of alkanes were higher than alkenes. However, with the increase of reaction time, the propene, ethylene, and hexene increased but the propane, butene, and butane decreased. Thus, the butene is supposed to be converted from the crack of hexene since the major products from $\mathrm{HDO}$ of acetone over $\mathrm{MoO}_{3}$ was reported to be propene and hexene (at low hydrogen pressure) $[14,20,23]$. From the change of aliphatic products with the increase of TOS, it is believed that the deactivation of the catalyst is gradual. The presence of $\mathrm{MoO}_{3}$ retarded the deactivation process and kept the catalysts at a relatively high active status. 

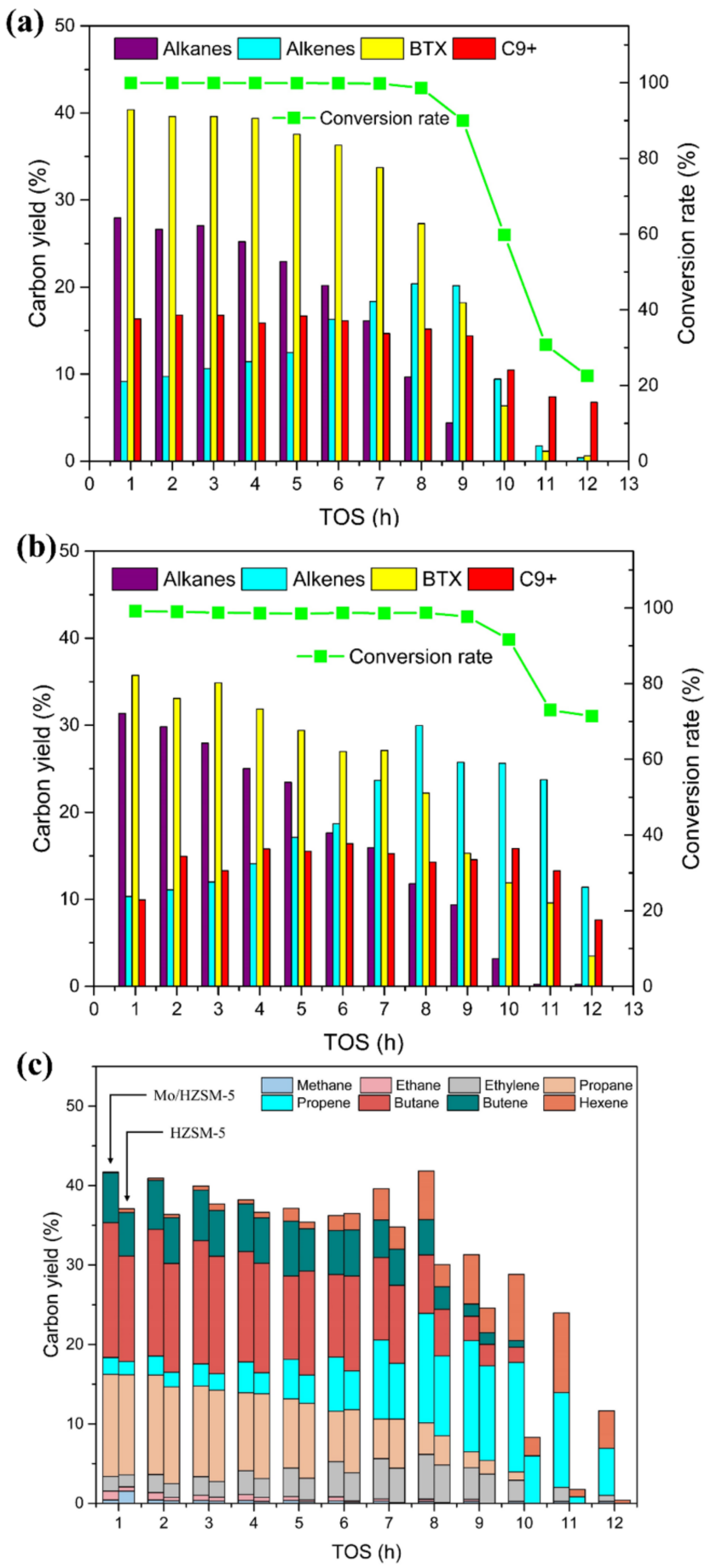

Figure 3. The results of HDO of acetone at atmospheric hydrogen pressure (a) conversion rate and major product groups distribution of HZSM-5, (b) conversion rate and major product groups distribution of Mo/HZSM-5, (c) detailed aliphatic product distribution, catalytic temperature: $400{ }^{\circ} \mathrm{C}$, hydrogen pressure: 0.1 bar, $\mathrm{W} / \mathrm{F}=0.073 \mathrm{~g}_{\text {cat }}\left(\mathrm{mmol}_{\text {feed }} \mathrm{h}^{-1}\right)^{-1}$.

The aromatic products from the acetone HDO tests were classified into two groups, BTX (benzene, toluene and xylene), and C9+ (the aromatics which their carbon numbers were higher than 9, mainly alkylbenzene, alkenylbenzene and naphthalene). From Figure $3 a$, we can see the yield of BTX over HZSM- 5 decreased from $40.4 \%$ to $0.6 \%$ with the increase of TOS. The decreasing rate was also accelerated with the increase of TOS. At the first four hours, the yield of BTX was kept at about $39.5 \%$. It dropped down to $27.1 \%$ with increasing TOS to $8 \mathrm{~h}$. Finally, the yield of aromatics decreased to only $0.6 \%$ at the 
TOS of $12 \mathrm{~h}$. Being different from the BTX formation, the yield of C9+ over HZSM-5 kept at about $16 \%$ at the first $8 \mathrm{~h}$ and dropped down to $6.8 \%$ at the TOS of $12 \mathrm{~h}$. In the case of Mo/HZSM-5, similar trend of the reduction of BTX was observed. It decreased from $35.7 \%$ to $22.2 \%$ with TOS increasing to $8 \mathrm{~h}$, then sharply dropped down to $3.5 \%$ in final $4 \mathrm{~h}$. However, as we can see from Figure 3b, Mo/HZSM-5 converted less BTX than HZSM- 5 in first $9 \mathrm{~h}$. The catalysts in first $9 \mathrm{~h}$ of experiments were considered at a relatively high catalytic activity. This may be caused by the high hydrodeoxygenation activity of the doped $\mathrm{MoO}_{3}$, which converted more acetone to form aliphatic products instead of being aromatized by HZSM-5. But in the last $3 \mathrm{~h}, \mathrm{Mo} / \mathrm{HZSM}-5$ converted more BTX than HZSM-5. Especially during the final $2 \mathrm{~h}$, there were only $1.1 \%$ and $0.6 \%$ of BTXs produced from HZSM-5, which for Mo/HZSM- 5 were $9.6 \%$ and $3.5 \%$, respectively. This is because the sharply deactivation of HZSM-5 with prolonged TOS, which resulted to the low conversion of acetone. This trend also indicates that doped $\mathrm{MoO}_{3}$ effectively retarded the deactivation of HZSM-5. The higher yield of BTXs for Mo/HZSM- 5 during the last two hours suggests that deactivation of pure HZSM- 5 was more significant than the HZSM- 5 part of Mo/HZSM-5. The yield of C9+ from HZSM-5 kept at $\sim 16.5 \%$ in first $6 \mathrm{~h}$, then reduced to $6.8 \%$ in the last $6 \mathrm{~h}$. Similar with the case of BTX, Mo/HZSM- 5 obtained lower yield of C $9+$ in first $9 \mathrm{~h}$ but higher yield in last $3 \mathrm{~h}$. The yield of C $9+$ from Mo/HZSM- 5 peaked at the 6 th hour with a value of $16.4 \%$ before reduced to $7.6 \%$ at the 12 th hour. This trend also suggests the doped $\mathrm{MoO}_{3}$ could retard the deactivation of HZSM-5.

\subsubsection{Influence of Hydrogen Pressure on Hydrodeoxygenation of Acetone}

It is believed that high hydrogen pressure could promote the hydrodeoxygenation and suppress the formation of coke [1]. The HDO experiments of acetone at 30 bar hydrogen pressure over Mo/HZSM- 5 and HZSM- 5 were conducted. Figure $4 a$, b shows the overall conversion rate and major products formation with the increase of TOS. We can immediately find the conversion rate of both the catalysts were rather stable at about $100 \%$ in total $12 \mathrm{~h}$ of tests. The yields of the major products also exhibited a relatively stable trend. It is believed that the increase hydrogen pressure retarded the coke formation and prolonged the active time of catalysts. As we know, the main reason for the deactivation of HZSM-5 was the formation of coke resulting to the cover of catalytic active site [31]. The coke was reported to be the polymeric aromatics and oxygenates [32]. High hydrogen pressure would contribute to the saturation of these coke precursor, which would prevent them from further polymerization to form coke.

The higher hydrogen pressure strongly enhanced the formation of alkanes for HZSM-5. The yield of alkanes over HZSM-5 slightly decreased from $40 \%$ to $31.6 \%$ with the increase of TOS. Corresponding to the reduction of alkanes, the yield of alkenes slightly increased from $5.5 \%$ to $9.4 \%$ with the increase of TOS. The change of the yield of alkanes and alkenes with the increase of TOS indicated the gradual deactivation of HZSM-5. However, compared to the case of atmospheric hydrogen pressure, the deactivation rate of higher hydrogen pressure was rather slow. It is suggested that the increased hydrogen pressure retarded the deactivation of HZSM-5. Furthermore, the yield of alkanes from $30 \mathrm{bar}$ hydrogen pressure was much higher than that from atmospheric hydrogen pressure, which decreased from $27.9 \%$ to $0 \%$ in $12 \mathrm{~h}$. Apparently, the increased hydrogen pressure enhanced the hydrogenation of alkenes. Figure $4 \mathrm{c}$ exhibited the detailed product distribution of aliphatics (alkanes and alkenes) for two catalysts at 30 bar hydrogen pressure. We can find no ethylene and propene were obtained. The only alkenes remained were the butene and a small number of hexene. The enhanced hydrogenation activity by increased hydrogen pressure saturated all the ethylene and propene to form the corresponding alkanes. For Mo/HZSM-5, similar trend was observed. The yield of alkanes gently decreased from $53.8 \%$ to $45.3 \%$ with the increase of TOS. The yield of alkenes increased from $8.9 \%$ to $11.5 \%$ with the increase of TOS. Compared to the case of Mo/HZSM-5 at atmospheric hydrogen pressure, the formation of alkanes was enhanced with the increase of hydrogen pressure. However, the yield of alkanes obtained from 30 bar hydrogen pressure was $32.4 \%$ 
higher than that from atmospheric pressure for Mo/HZSM-5, which for HZSM-5 was 21.1\% higher. It indicates that the doped $\mathrm{MoO}_{3}$ further enhanced the formation of alkanes by the increased hydrogen pressure. This is because the presence of $\mathrm{MoO}_{3}$ enhanced the direct hydrodeoxygenation of acetone and increase the total aliphatic products (average 59.0\% for Mo/HZSM-5 and 44.6\% for HZSM-5).
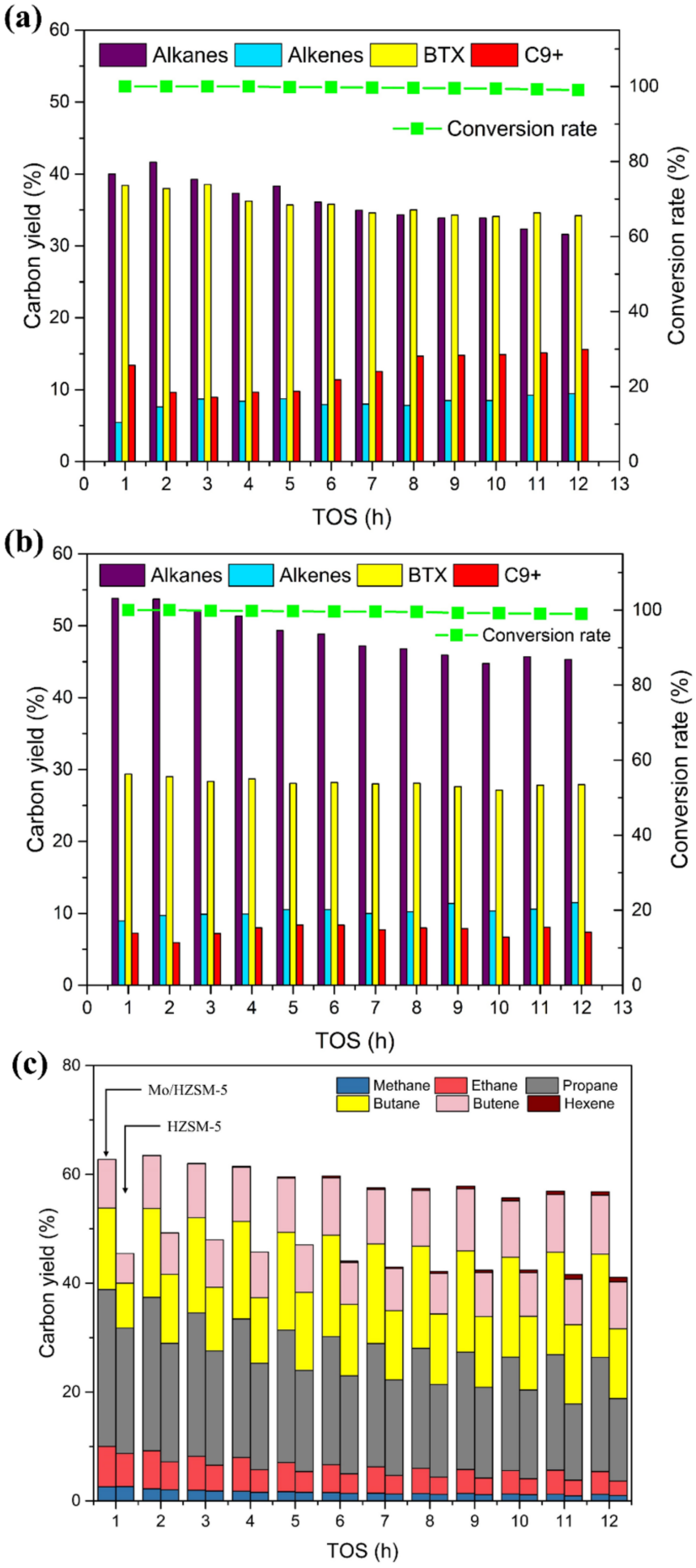

Figure 4. The results of HDO of acetone at 30 bar hydrogen pressure (a) conversion rate and major product groups distribution of HZSM-5, (b) conversion rate and major product groups distribution of Mo/HZSM-5, (c) detailed aliphatic product distribution, catalytic temperature: $400{ }^{\circ} \mathrm{C}$, hydrogen pressure: 30 bar, $\mathrm{W} / \mathrm{F}=0.073 \mathrm{~g}_{\text {cat }}\left(\mathrm{mmol}_{\text {feed }} \mathrm{h}^{-1}\right)^{-1}$. 
From Figure 4a, we can find the yield of BTX for HZSM- 5 at 30 bar was quite stable, compared to that at atmospheric pressure. It decreased gently from $38.4 \%$ to $34.6 \%$ with the increase of TOS. The average yield of BTX at 30 bar pressure (36.0\%) was higher than that at atmospheric pressure $(26.7 \%)$. Interestingly, we can notice that the yield of BTX under different hydrogen pressure was close, compared to that for HZSM- 5 at atmospheric hydrogen pressure in the first $4 \mathrm{~h}$ of test (average 39.5\%). The close yield of BTX may indicate that the increase of the hydrogen pressure had no promotion to the formation of BTX over HZSM-5. The increase of average yield of BTX in $12 \mathrm{~h}$ of experiment $(36.0 \%$ at 30 bar and $26.7 \%$ at atmospheric pressure) could be ascribed to the anti-deactivation and prolonged active time caused by the increased hydrogen pressure. From Figure $4 \mathrm{~b}$, we can observe that the yield of BTX for Mo/HZSM- 5 at 30 bar hydrogen pressure slightly decreased from $29.4 \%$ to $27.9 \%$ with the increase of TOS. Similar trend with aliphatic products, which indicated the stable status of catalysts. The average yield of BTX for Mo/HZSM- 5 at 30 bar was $28.2 \%$, which is higher than that at atmospheric pressure (23.5\%). However, when comparing the average yield in first four hours $(28.7 \%$ at 30 bar and $34.8 \%$ at atmospheric pressure), we can find the obvious reduction of BTX. Additionally, the average yield of BTX for Mo/HZSM-5 was $9.8 \%$ lower than that for HZSM- 5 at 30 bar. The reduction of BTX of Mo/HZSM- 5 was caused by the facilitated direct hydrodeoxygenation by doped $\mathrm{MoO}_{3}$. As we stated above at Section 3.2.1, more acetone was converted to aliphatics instead of aromatization. The increased hydrogen pressure enhanced the direct hydrodeoxygenation activity of doped $\mathrm{MoO}_{3}$ with the decreasing BTX yield. The yield of C 9 + for HZSM- 5 at 30 bar decreased from $13.4 \%$ to $9.0 \%$ in the first $3 \mathrm{~h}$ then increased to $15.6 \%$. The slightly reduction of $\mathrm{C} 9+$ in the beginning of test may be attributed to the high catalytic activity of fresh catalysts. Compared to the case at atmospheric pressure, we can find the increased hydrogen pressure could reduce the formation of $\mathrm{C} 9+$ aromatics. The average yield of C $9+$ for HZSM- 5 at 30 bar was $12.5 \%$, which at atmospheric pressure was $14.0 \%$. This trend was more obvious in the case of Mo/HZSM- 5 . As we can see from Figure $4 \mathrm{~b}$, the yield of $\mathrm{C} 9+$ for Mo/HZSM- 5 at 30 bar decreased from $7.2 \%$ to $5.9 \%$ in the first $2 \mathrm{~h}$, then gradually increased to $7.3 \%$ with TOS increasing to $12 \mathrm{~h}$. The average yield of C $9+$ for Mo/HZSM- 5 at 30 bar was $7.6 \%$, which at atmospheric pressure was $13.9 \%$. The saturation tendency caused by the doped $\mathrm{MoO}_{3}$ and increased hydrogen pressure may prevent the small alkenes from the aromatization and polymerization.

It is obvious that the promotion of $\mathrm{HDO}$ process caused by doped $\mathrm{MoO}_{3}$ was further enhanced by the higher hydrogen pressure. Thus, HDO of acetone in fixed bed with Mo/HZSM- 5 at different hydrogen pressures (10 bar, 20 bar and 30 bar) was conducted to investigate the influence of hydrogen pressure. Figure 5 exhibited the conversion rate and major products distribution for Mo/HZSM- 5 at different hydrogen pressure. As we can see from Figure $5 \mathrm{a}$, the hydrogen pressure could effectively prolong the active time of catalysts. The conversion rate for all higher hydrogen pressure levels were nearly $100 \%$ in $12 \mathrm{~h}$ of experiments. From Figure 5b, we can find the enhancement of the formation of alkanes by the hydrogen pressure was obvious. The yields of alkanes for all higher hydrogen pressure levels were higher than the atmospheric pressure. The yields of alkanes at $30 \mathrm{bar}$ and $20 \mathrm{bar}$ were also higher than that at $10 \mathrm{bar}$ (average $44.1 \%$ ). But the yields of alkanes were similar at $20 \mathrm{bar}$ and $30 \mathrm{bar}$, and the average yield at $30 \mathrm{bar}(48.7 \%)$ even slightly lower than that at 20 bar (50.0\%). It suggests that the increased hydrogen would enhance the formation of alkanes, but the enhancement may have a restraint. Corresponding to the alkanes, the yield of alkenes was reduced by the increased hydrogen pressure. However, different with alkanes, the yield of alkenes at all hydrogen pressure levels was rather close (average $9.6 \%$ at $10 \mathrm{bar}, 9.9 \%$ at $20 \mathrm{bar}$, and $10.3 \%$ at $30 \mathrm{bar}$ ). For Mo/HZSM-5, the increased hydrogen pressure also decreased the formation of BTX, and the yield decreased with the increased pressure. The average yield of BTX was $31.2 \%, 29.7 \%$ and $28.2 \%$ at $10 \mathrm{bar}, 20 \mathrm{bar}$ and 30 bar, respectively. It is noticed that the yield of BTX in the first four hours at atmospheric pressure was higher than that at all higher hydrogen pressure (Figure 5d). The Figure 5e also showed the yield of $\mathrm{C} 9+$ was decreased with the increased hydrogen pressure. The 
trend of saturation caused by the increased hydrogen pressure prevented the small alkenes from further aromatization and polymerization.

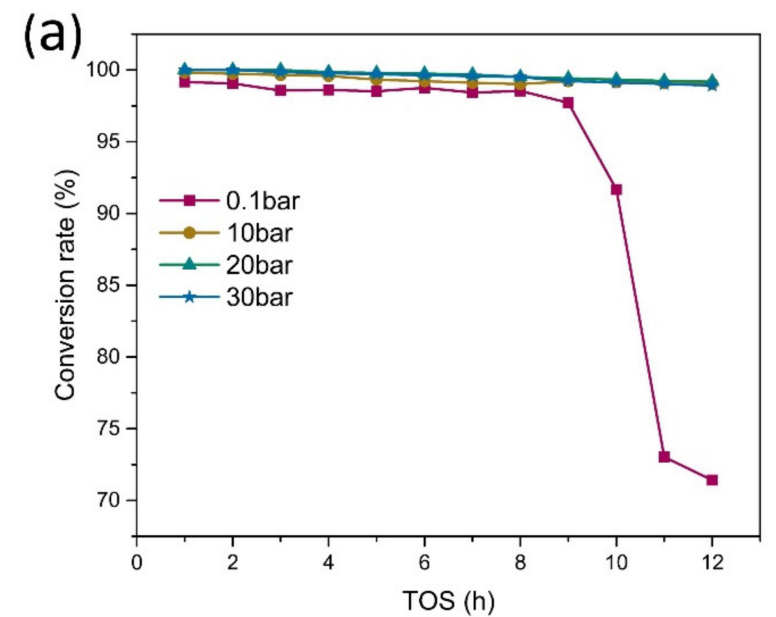

(b)

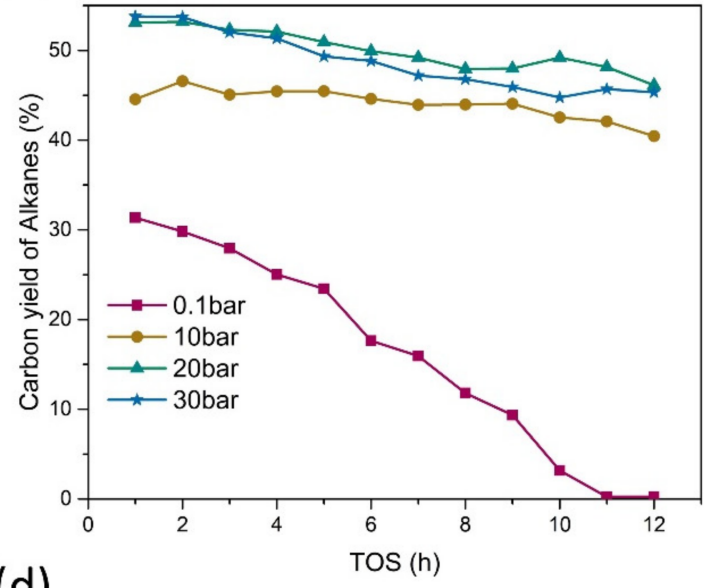

(d)

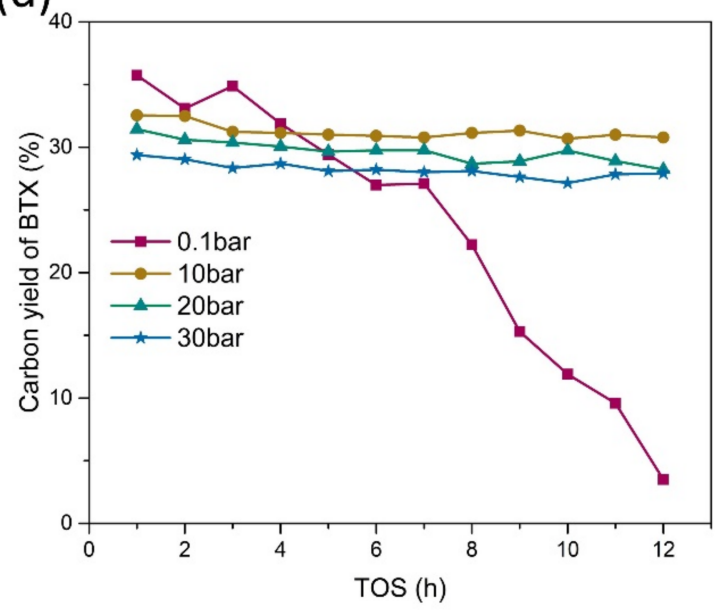

(c)

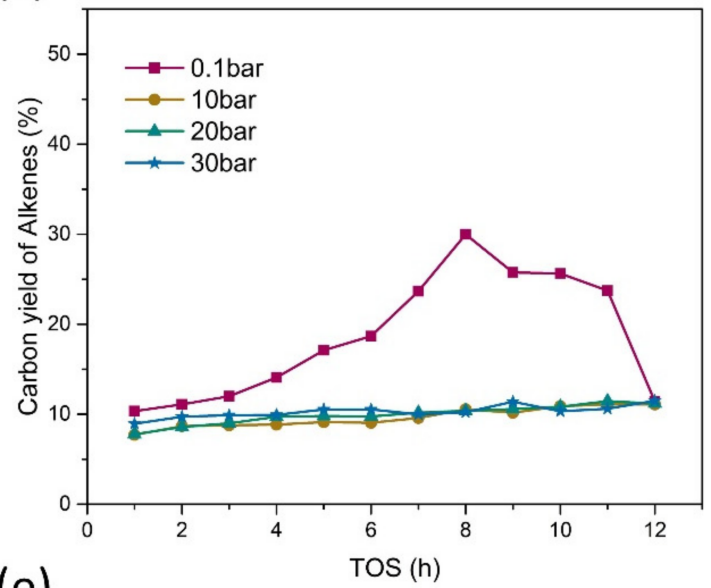

(e)

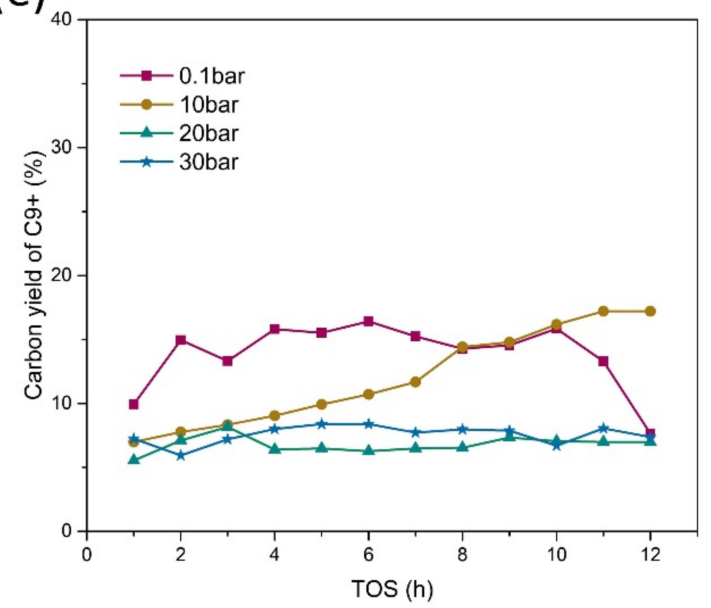

Figure 5. Conversion rate and major product distribution with different hydrogen pressure (catalytic temperature: $400{ }^{\circ} \mathrm{C}, \mathrm{W} / \mathrm{F}=0.073 \mathrm{~g}_{\text {cat }}\left(\mathrm{mmol}_{\text {feed }} \mathrm{h}^{-1}\right)^{-1}$ : (a) conversion rate, (b) alkanes, (c) alkenes, (d) MAHs, (e) PAHs)

\subsection{Characterization of the Spent Catalysts}

To investigate the influence of the coke deposited on the catalysts, we characterized the spent catalysts with elemental analysis, $\mathrm{N}_{2}$ physisorption isotherm, and $\mathrm{NH}_{3}$-TPD. Table 2 exhibited the texture properties and acidity of the spent catalysts. The carbon yield of coke 
was calculated for the total $12 \mathrm{~h}$. HZSM-5 at atmospheric pressure converted the highest coke $(17.2 \%)$, and Mo/HZSM-5 converted the lowest coke (2.3\%). Increased hydrogen pressure obviously suppressed the coke deposition.

Table 2. Summary of texture properties and acidity of spent catalysts.

\begin{tabular}{|c|c|c|c|c|}
\hline \multirow{2}{*}{$\begin{array}{c}\text { Spent Catalyst } \\
\text { Catalysis pressure/bar }\end{array}$} & \multicolumn{2}{|c|}{ HZSM-5 } & \multicolumn{2}{|c|}{ Mo/HZSM-5 } \\
\hline & 0.1 & 30 & 0.1 & 30 \\
\hline Coke $(\mathrm{C} \%)$ & 17.2 & 5.8 & 13.4 & 2.3 \\
\hline Surface area $\left(\mathrm{m}^{2} / \mathrm{g}\right)$ & 14 & 142 & 41 & 230 \\
\hline${ }^{a} V_{\text {micro }}\left(\mathrm{m}^{3} / \mathrm{g}\right)$ & 0.001 & 0.044 & 0.011 & 0.084 \\
\hline b $V_{\text {meso }}\left(\mathrm{m}^{3} / \mathrm{g}\right)$ & 0.033 & 0.043 & 0.033 & 0.045 \\
\hline${ }^{c} V_{\text {total }}\left(\mathrm{m}^{3} / \mathrm{g}\right)$ & 0.034 & 0.087 & 0.044 & 0.129 \\
\hline \multicolumn{5}{|l|}{ Lewis acid } \\
\hline Density (mmol/g) & 0.470 & 0.594 & 0.654 & 0.813 \\
\hline Peak position $\left({ }^{\circ} \mathrm{C}\right)$ & 131.8 & 140.0 & 136.4 & 144.1 \\
\hline \multicolumn{5}{|l|}{ Bronsted acid } \\
\hline Density (mmol/g) & & 0.76 & & 0.163 \\
\hline Peak position $\left({ }^{\circ} \mathrm{C}\right)$ & & 394.6 & & 402.3 \\
\hline
\end{tabular}

${ }^{\mathrm{a}}$ Calculated by the $t$-polt method. ${ }^{\mathrm{b}}$ Calculated by subtracting $\mathrm{V}_{\text {micro }}$ from $\mathrm{V}_{\text {total }} \cdot{ }^{\mathrm{c}}$ Calculated by the BJH method.

Additionally, it is noticed that the surface area and pore volume of the spent catalysts under atmospheric pressure were rather low. At atmospheric pressure, the surface area of HZSM-5 decreased from 397 to $14 \mathrm{~m}^{2} / \mathrm{g}$ and the pore volume decreased from 0.206 to $0.034 \mathrm{~m}^{3} / \mathrm{g}$. It is noticeable that the micropore volume was only $0.001 \mathrm{~m}^{3} / \mathrm{g}$, which indicated that spent catalysts were almost totally deactivated. Since the acid catalytic sites of ZSM-5 were mainly located in its micropores [33]. This was in line with our HDO results at atmospheric pressure, which the HZSM-5 was almost deactivated at the end of the experiments. The similar phenomenon was also observed from the spent Mo/HZSM-5 at atmospheric pressure. Compared to the fresh catalysts, the surface area of spent Mo/HZSM5 under atmospheric hydrogen pressure decreased from $367 \mathrm{~m}^{2} / \mathrm{g}$ to $41 \mathrm{~m}^{2} / \mathrm{g}$. The total pores volume decreased from $0.188 \mathrm{~m}^{3} / \mathrm{g}$ to $0.044 \mathrm{~m}^{3} / \mathrm{g}$ and the micropore volume was $0.011 \mathrm{~m}^{3} / \mathrm{g}$. The HDO process at atmospheric pressure also deactivated the Mo/HZSM-5, but it is not as severe as the case of HZSM-5. It can be observed that the spent Mo/HZSM-5 had higher surface area and micropore volume than HZSM-5. This trend suggested that the doped $\mathrm{MoO}_{3}$ decreased the coke formation of HZSM-5 during the HDO process. However, the promotion of $\mathrm{MoO}_{3}$ at atmospheric pressure was limited. After $12 \mathrm{~h}$ of experiments, the Mo/HZSM-5 was also close to deactivation and the surface area and micropore volumes was only slightly higher than the spent HZSM-5.

Higher pressure hydrogen remarkably promoted the catalytic process and suppressed the coke. The surface area of spent HZSM- 5 at 30 bar was $142 \mathrm{~m}^{2} / \mathrm{g}$. It was $255 \mathrm{~m}^{2} / \mathrm{g}$ lower than that of fresh HZSM-5, but $128 \mathrm{~m}^{2} / \mathrm{g}$ higher than that of spent HZSM-5 at atmospheric pressure. The micropore volume of HZSM-5 at 30 bar was $0.044 \mathrm{~m}^{3} / \mathrm{g}$, which is $0.043 \mathrm{~m}^{3} / \mathrm{g}$ higher than that of HZSM-5 at atmospheric pressure. But it decreased $0.078 \mathrm{~m}^{3} / \mathrm{g}$ of micropore volume than fresh HZSM-5. This trend to a certain extent proved that the coke formation was still gradually accumulated when the conversion rate was about $100 \%$. In the case of Mo/HZSM-5 at 30 bar, the surface area of spent catalysts was $230 \mathrm{~m}^{2} / \mathrm{g}$ and the micropore volume was $0.084 \mathrm{~m}^{3} / \mathrm{g}$. It was rather higher than that of spent Mo/HZSM-5 at atmospheric pressure, which is $0.073 \mathrm{~m}^{3} / \mathrm{g}$ higher. The surface area of spent Mo/HZSM- 5 was $137 \mathrm{~m}^{2} / \mathrm{g}$ lower than that of fresh Mo/HZSM-5 and the micropore volume was only $0.038 \mathrm{~m}^{3} / \mathrm{g}$ lower than that of fresh Mo/HZSM-5. Compared to the fresh catalysts at 30 bar, the spent Mo/HZSM-5 reduced much less micropore volume and surface area than the spent HZSM-5. This indicated that under higher hydrogen pressure, doped $\mathrm{MoO}_{3}$ remarkably suppressed the coke formation and prolonged the active time of catalysts. The increased hydrogen pressure effectively promoted the HDO process over metal doped HZSM-5. 
From the results of $\mathrm{NH}_{3}$-TPD, we can find that the coke remarkably effected the acidity of catalysts. Under atmospheric pressure, the Lewis acid density of spent HZSM-5 decreased to $0.470 \mathrm{mmol} / \mathrm{g}$ from $1.158 \mathrm{mmol} / \mathrm{g}$ for fresh HZSM-5. The Lewis acid density of spent Mo/HZSM-5 decreased to $0.654 \mathrm{mmol} / \mathrm{g}$ from $1.223 \mathrm{mmol} / \mathrm{g}$ for fresh Mo/HZSM-5. It could be noticed that the Bronsted acid density of both the catalysts were decreased to zero. From the image of $\mathrm{NH}_{3}$-TPD results (Figure S1), we could observe that there were nearly no peaks appearing at around $400{ }^{\circ} \mathrm{C}$ desorption temperature for spent catalysts at atmospheric pressure. It is noticed that there are also no micropores volume for the spent catalysts under atmospheric pressure. This may indicate the Bronsted acid site were mainly in the micropores of zeolites. These results were in correspondence with the HDO results at atmospheric hydrogen pressure, which the catalysts were almost deactivated at the end of experiments. It is believed that Bronsted acid of HZSM-5 played a dominant role in the catalytic deoxygenation of oxygenate compounds $[5,9]$.

In the case of 30 bar hydrogen pressure, the reduction of acid sites was retarded. Under 30 bar hydrogen pressure, the Lewis acid density of spent HZSM-5 decreased to $0.594 \mathrm{mmol} / \mathrm{g}$, while that of spent Mo/HZSM-5 decreased to $0.813 \mathrm{mmol} / \mathrm{g}$. In contrast to the result of atmospheric pressure, the Bronsted acid density of spent HZSM- 5 and Mo/HZSM-5 under 30 bar hydrogen pressure still remain $0.076 \mathrm{mmol} / \mathrm{g}$ and $0.163 \mathrm{mmol} / \mathrm{g}$, respectively. The spent Mo/HZSM-5 had a higher Bronsted acid density and mircopore volumes than spent HZSM-5. This result suggested that most of the Bronsted acid sites of HZSM-5 were in the micropore structure. The higher Bronsted acid density of Mo/HZSM-5 also indicated that 30 bar hydrogen pressure remarkably promoted the HDO over Mo/HZSM-5 and reduced the coke.

\subsection{Reaction Network of Catalytic HDO of Acetone over Mo/HZSM-5}

Figure 6 showed the supposed reaction network of catalytic HDO of acetone over Mo/HZSM-5. Based on the HDO results under higher hydrogen pressure of the current study, it is believed that Mo/HSM5 tended to preferentially convert acetone to C3 and C4 aliphatic products, then aromatic products. When the catalytic activity deteriorated, the $\mathrm{C} 6$ and $\mathrm{C} 2$ aliphatic products increased, but the $\mathrm{C} 3$ and $\mathrm{C} 4$ reduced. Thus, we supposed the $\mathrm{C} 6$ aliphatic products were converted from the $\mathrm{C}-\mathrm{C}$ coupling reaction of hydrodeoxygenated acetone. The C4 and C2 products were produced from the cracking reaction from C6 products, and the $\mathrm{C} 2$ products would further undergo a $\mathrm{C}-\mathrm{C}$ coupling reaction to form $\mathrm{C} 4$ products under high catalytic activity. The produced aromatic products were predominantly converted by the "hydrocarbon pool" mechanism [34]. However, the hydrogen pressure could further enhance the formation of aliphatic products over doped $\mathrm{MoO}_{3}$. 


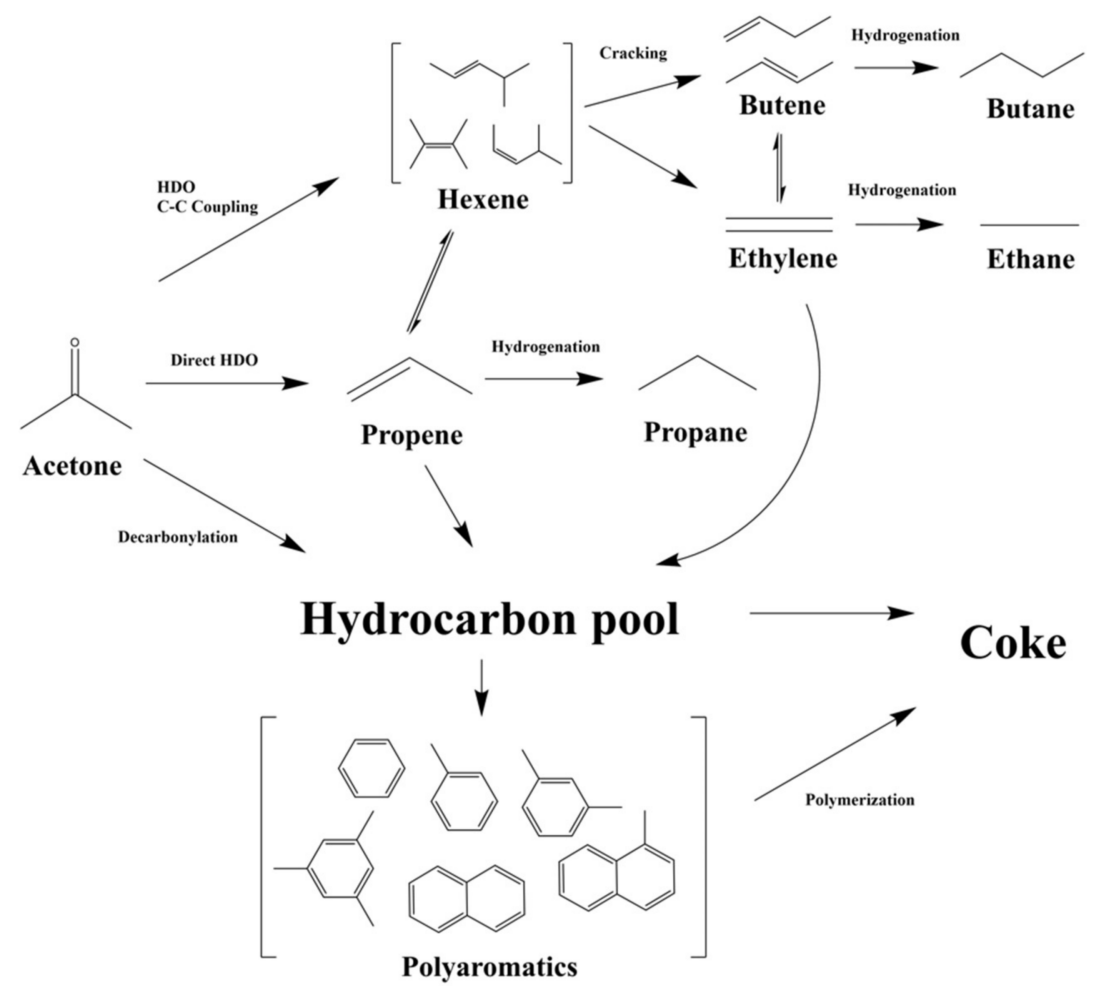

Figure 6. Supposed reaction network of catalytic HDO of acetone over Mo/HZSM-5.

\section{Conclusions}

In the current study, we conducted the catalytic HDO experiments using acetone as mode compound to investigate the role of dispersed $\mathrm{MoO}_{3}$ in the hydrodeoxygenation process over Mo/HZSM-5. We found that under atmospheric hydrogen pressure, doped $\mathrm{MoO}_{3}$ could enhance the formation of aliphatic products and decreased the coke. The yield of aliphatics for Mo/HZSM-5 increased 31\%, compared to that from HZSM-5. The coke yield of spent Mo/HZSM- 5 was $22 \%$ lower than that of spent HZSM-5. We further investigated the influence of higher hydrogen pressure on catalytic HDO of acetone. The results at 30 bar hydrogen pressure showed the increased hydrogen pressure could effectively prolong the catalyst activity and suppress the coke. The coke of HZSM-5 and Mo/HZSM5 decreased $66 \%$ and $83 \%$, respectively, compared to that under atmospheric hydrogen pressure. The increased hydrogen pressure also enhanced the hydrodeoxygenation and hydrogenation reaction over doped $\mathrm{MoO}_{3}$ and converted $72 \%$ higher yield of aliphatics over Mo/HZSM-5. Generally, the doped $\mathrm{MoO}_{3}$ facilitated the direct hydrodeoxygenation of acetone, reduced the coke, and prolonged the active time of catalysts. However, the promotion of aliphatics and the reduction of aromatics over Mo/HZSM- 5 in the current study was only responsible for the catalytic HDO of acetone. In order to fully understand the mechanism of catalytic hydropyrolysis and coke deposition over Mo/HZSM-5, other types of model compounds (e.g., furans and phenols) and their interactive reaction are needed to be further investigated.

Supplementary Materials: The following supporting information can be downloaded at: https: / / www.mdpi.com/article/10.3390/en15010053/s1, Figure S1: The results of $\mathrm{NH}_{3}$-TPD for spent catalysts; Table S1: Summary of detailed calibration coefficient.

Author Contributions: Conceptualization, K.M. and K.W.; Data Curation, K.M. and T.L.; Formal analysis, K.M.; Funding Acquisition, K.W.; Investigation, K.M., J.S. and C.W.; Project Administration, K.W.; Supervision, K.W.; Validation, T.L. and K.W.; Writing-Original Draft, K.M.; Writing-Review and Editing, K.W. All authors have read and agreed to the published version of the manuscript. 
Funding: This research was funded by National Natural Science Foundation of China, grant number 51906215.

Institutional Review Board Statement: Not applicable.

Informed Consent Statement: Not applicable.

Data Availability Statement: Not applicable.

Acknowledgments: The authors would like to acknowledge financial support from the National Natural Science Foundation of China (Grant No.: 51906215) and the Fundamental Research Funds for the Central Universities.

Conflicts of Interest: The authors declare that they have no known competing financial interests or personal relationships that could have appeared to influence the work reported in this paper.

\section{References}

1. Dabros, T.M.H.; Stummann, M.Z.; Høj, M.; Jensen, P.A.; Grunwaldt, J.-D.; Gabrielsen, J.; Mortensen, P.M.; Jensen, A.D. Transportation fuels from biomass fast pyrolysis, catalytic hydrodeoxygenation, and catalytic fast hydropyrolysis. Prog. Energy Combust. Sci. 2018, 68, 268-309. [CrossRef]

2. Liu, Z.; Hughes, M.; Tong, Y.; Zhou, J.; Kreutter, W.; Lopez, H.C.; Singer, S.; Zitomer, D.; McNamara, P. Paper mill sludge biochar to enhance energy recovery from pyrolysis: A comprehensive evaluation and comparison. Energy 2022, 239, 121925. [CrossRef]

3. Liu, C.; Wang, H.; Karim, A.M.; Sun, J.; Wang, Y. Catalytic fast pyrolysis of lignocellulosic biomass. Chem. Soc. Rev. 2014, 43, 7594-7623. [CrossRef]

4. Zahra, H.; Sawada, D.; Kumagai, S.; Ogawa, Y.; Johansson, L.-S.; Ge, Y.; Guizani, C.; Yoshioka, T.; Hummel, M. Evolution of carbon nanostructure during pyrolysis of homogeneous chitosan-cellulose composite fibers. Carbon 2021, 185, 27-38. [CrossRef]

5. Saraeian, A.; Burkhow, S.J.; Jing, D.; Smith, E.A.; Shanks, B.H. Catalyst Property Effects on Product Distribution during the Hydrodeoxygenation of Lignin Pyrolysis Vapors over $\mathrm{MoO}_{3} / \gamma-\mathrm{Al}_{2} \mathrm{O}_{3}$. ACS Sustain. Chem. Eng. 2021, 9, 6685-6696. [CrossRef]

6. Williams, P.T.; Nugranad, N. Comparison of products from the pyrolysis and catalytic pyrolysis of rice husks. Energy 2000, 25, 493-513. [CrossRef]

7. Mastral, J.F.; Berrueco, C.; Gea, M.; Ceamanos, J. Catalytic degradation of high density polyethylene over nanocrystalline HZSM-5 zeolite. Polym. Degrad. Stab. 2006, 91, 3330-3338. [CrossRef]

8. Stefanidis, S.D.; Kalogiannis, K.G.; Iliopoulou, E.F.; Lappas, A.A.; Pilavachi, P.A. In-situ upgrading of biomass pyrolysis vapors: Catalyst screening on a fixed bed reactor. Bioresour. Technol. 2011, 102, 8261-8267. [CrossRef]

9. Puertolas, B.; Veses, A.; Callen, M.S.; Mitchell, S.; Garcia, T.; Perez-Ramirez, J. Porosity-Acidity Interplay in Hierarchical ZSM-5 Zeolites for Pyrolysis Oil Valorization to Aromatics. ChemSusChem 2015, 8, 3283-3293. [CrossRef] [PubMed]

10. Zheng, N.; Zhang, J.; Wang, J. Parametric study of two-stage hydropyrolysis of lignocellulosic biomass for production of gaseous and light aromatic hydrocarbons. Bioresour. Technol. 2017, 244 Pt 1, 142-150. [CrossRef] [PubMed]

11. Carlson, T.R.; Tompsett, G.A.; Conner, W.C.; Huber, G.W. Aromatic Production from Catalytic Fast Pyrolysis of Biomass-Derived Feedstocks. Top. Catal. 2009, 52, 241-252. [CrossRef]

12. Zhang, H.; Xiao, R.; Huang, H.; Xiao, G. Comparison of non-catalytic and catalytic fast pyrolysis of corncob in a fluidized bed reactor. Bioresour. Technol. 2009, 100, 1428-1434. [CrossRef]

13. Cheng, S.; Wei, L.; Julson, J.; Rabnawaz, M. Upgrading pyrolysis bio-oil through hydrodeoxygenation (HDO) using non-sulfided Fe-Co/SiO 2 catalyst. Energy Convers. Manag. 2017, 150, 331-342. [CrossRef]

14. Prasomsri, T.; Shetty, M.; Murugappan, K.; Román-Leshkov, Y. Insights into the catalytic activity and surface modification of $\mathrm{MoO}_{3}$ during the hydrodeoxygenation of lignin-derived model compounds into aromatic hydrocarbons under low hydrogen pressures. Energy Environ. Sci. 2014, 7, 2660-2669. [CrossRef]

15. Aqsha, A.; Katta, L.; Tijani, M.M.; Oliveira, C.F.; Mahinpey, N. Investigation of catalytic hydrodeoxygenation of anisole as bio-oil model compound over $\mathrm{Ni}-\mathrm{Mo} / \mathrm{TiO}_{2}$ and $\mathrm{Ni}-\mathrm{V} / \mathrm{TiO}_{2}$ catalysts: Synthesis, kinetic, and reaction pathways studies. Can. J. Chem. Eng. 2020, 99, 1094-1106. [CrossRef]

16. Marker, T.L.; Felix, L.G.; Linck, M.B.; Roberts, M.J.; Ortiz-Toral, P.; Wangerow, J. Integrated hydropyrolysis and hydroconversion $\left(\mathrm{IH} 2{ }^{\circledR}\right)$ for the direct production of gasoline and diesel fuels or blending components from biomass, Part 2: Continuous testing. Environ. Prog. Sustain. Energy 2014, 33, 762-768. [CrossRef]

17. Marker, T.L.; Felix, L.G.; Linck, M.B.; Roberts, M.J. Integrated hydropyrolysis and hydroconversion (IH2) for the direct production of gasoline and diesel fuels or blending components from biomass, Part 1: Proof of principle testing. Environ. Prog. Sustain. Energy 2012, 31, 191-199. [CrossRef]

18. Rasmussen, M.J.; Medlin, J.W. Role of tungsten modifiers in bimetallic catalysts for enhanced hydrodeoxygenation activity and selectivity. Catal. Sci. Technol. 2020, 10, 414-423. [CrossRef]

19. Eschenbacher, A.; Saraeian, A.; Shanks, B.H.; Mentzel, U.V.; Jensen, P.A.; Henriksen, U.B.; Ahrenfeldt, J.; Jensen, A.D. Performancescreening of metal-impregnated industrial HZSM- $5 / \gamma-\mathrm{Al}_{2} \mathrm{O}_{3}$ extrudates for deoxygenation and hydrodeoxygenation of fast pyrolysis vapors. J. Anal. Appl. Pyrolysis 2020, 150, 104892. [CrossRef] 
20. Prasomsri, T.; Nimmanwudipong, T.; Román-Leshkov, Y. Effective hydrodeoxygenation of biomass-derived oxygenates into unsaturated hydrocarbons by $\mathrm{MoO}_{3}$ using low $\mathrm{H}_{2}$ pressures. Energy Environ. Sci. 2013, 6, 1732-1738. [CrossRef]

21. Nolte, M.W.; Saraeian, A.; Shanks, B.H. Hydrodeoxygenation of cellulose pyrolysis model compounds using molybdenum oxide and low pressure hydrogen. Green Chem. 2017, 19, 3654-3664. [CrossRef]

22. Murugappan, K.; Mukarakate, C.; Budhi, S.; Shetty, M.; Nimlos, M.R.; Román-Leshkov, Y. Supported molybdenum oxides as effective catalysts for the catalytic fast pyrolysis of lignocellulosic biomass. Green Chem. 2016, 18, 5548-5557. [CrossRef]

23. Shetty, M.; Murugappan, K.; Green, W.H.; Román-Leshkov, Y. Structural Properties and Reactivity Trends of Molybdenum Oxide Catalysts Supported on Zirconia for the Hydrodeoxygenation of Anisole. ACS Sustain. Chem. Eng. 2017, 5, 5293-5301. [CrossRef]

24. Xue, Y.; Sharma, A.; Huo, J.; Qu, W.; Bai, X. Low-pressure two-stage catalytic hydropyrolysis of lignin and lignin-derived phenolic monomers using zeolite-based bifunctional catalysts. J. Anal. Appl. Pyrolysis 2020, 146, 104779. [CrossRef]

25. Thangalazhy-Gopakumar, S.; Adhikari, S.; Gupta, R.B. Catalytic Pyrolysis of Biomass over H+ZSM-5 under Hydrogen Pressure. Energy Fuels 2012, 26, 5300-5306. [CrossRef]

26. Li, Z.; Zhong, Z.; Yang, Q.; Ben, H.; Seufitelli, G.V.S.; Resende, F.L.P. Parametric study of catalytic hydropyrolysis of rice husk over a hierarchical micro-mesoporous composite catalyst for production of light alkanes, alkenes, and liquid aromatic hydrocarbons. Fuel 2021, 310, 122475. [CrossRef]

27. Venkatakrishnan, V.K.; Degenstein, J.C.; Smeltz, A.D.; Delgass, W.N.; Agrawal, R.; Ribeiro, F.H. High-pressure fast-pyrolysis, fast-hydropyrolysis and catalytic hydrodeoxygenation of cellulose: Production of liquid fuel from biomass. Green Chem. 2014, 16, 792-802. [CrossRef]

28. Iisa, K.; Kim, Y.; Orton, K.A.; Robichaud, D.J.; Katahira, R.; Watson, M.J.; Wegener, E.C.; Nimlos, M.R.; Schaidle, J.A.; Mukarakate, C.; et al. Ga/ZSM-5 catalyst improves hydrocarbon yields and increases alkene selectivity during catalytic fast pyrolysis of biomass with co-fed hydrogen. Green Chem. 2020, 22, 2403-2418. [CrossRef]

29. Sun, L.; Wang, Z.; Chen, L.; Yang, S.; Xie, X.; Zhao, B.; Si, H.; Li, J.; Hua, D. Improving the monocyclic aromatic hydrocarbons production from fast pyrolysis of biomass over Fe-modified ZSM-5 catalysts. Int. J. Energy Res. 2020, 45, 6032-6040. [CrossRef]

30. Mukarakate, C.; Watson, M.J.; ten Dam, J.; Baucherel, X.; Budhi, S.; Yung, M.M.; Ben, H.; Iisa, K.; Baldwin, R.M.; Nimlos, M.R. Upgrading biomass pyrolysis vapors over $\beta$-zeolites: Role of silica-to-alumina ratio. Green Chem. 2014, 16, 4891-4905. [CrossRef]

31. Lee, K.-Y.; Kang, M.-Y.; Ihm, S.-K. Deactivation by coke deposition on the HZSM-5 catalysts in the methanol-to-hydrocarbon conversion. J. Phys. Chem. Solids 2012, 73, 1542-1545. [CrossRef]

32. Zhang, H.; Shao, S.; Xiao, R.; Shen, D.; Zeng, J. Characterization of Coke Deposition in the Catalytic Fast Pyrolysis of Biomass Derivates. Energy Fuels 2013, 28, 52-57. [CrossRef]

33. Jae, J.; Tompsett, G.A.; Foster, A.J.; Hammond, K.D.; Auerbach, S.M.; Lobo, R.F.; Huber, G.W. Investigation into the shape selectivity of zeolite catalysts for biomass conversion. J. Catal. 2011, 279, 257-268. [CrossRef]

34. Johansson, R.; Hruby, S.L.; Rass-Hansen, J.; Christensen, C.H. The Hydrocarbon Pool in Ethanol-to-Gasoline over HZSM-5 Catalysts. Catal. Lett. 2008, 127, 1-6. [CrossRef] 